\title{
Atypical ectopic pregnancy: a nightmare for the gynaecologist
}

\author{
Bikram Bhardwaj, Aruna Menon, Souvik Nandy*, Santosh
}

Department of Obstetrics and Gynecology, AFMC, Pune, Maharashtra, India

Received: 12 September 2021

Revised: 11 October 2021

Accepted: 12 October 2021

\author{
*Correspondence: \\ Dr. Souvik Nandy, \\ E-mail: babai6073@gmail.com
}

Copyright: (C) the author(s), publisher and licensee Medip Academy. This is an open-access article distributed under the terms of the Creative Commons Attribution Non-Commercial License, which permits unrestricted non-commercial use, distribution, and reproduction in any medium, provided the original work is properly cited.

\begin{abstract}
Ectopic pregnancy is one of the leading causes of maternal morbidity and mortality in early pregnancy. Incidence of ectopic pregnancy is $2 \%$ of total reported pregnancies and is rising in the recent past due to increase in RTIs and STIs and even early diagnosis due to advancing technology. Classical triad of pain abdomen, bleeding p/v and amenorrhea is not present in all the cases which add to confusion in diagnosing these atypical presentations. A meticulous history and clinical examination along with combination of transvaginal ultrasound (TVS) and serum beta HCG levels (discriminatory zone) can aid in picking up these atypical cases as depicted in our study. Here, we discussed 7 cases of atypical presentations of ectopic pregnancy which reported to gynaecology OPD of a service hospital of armed forces in a span of 3 months. One patient had pregnancy test negative, one patient was repeatedly treated as a case of AUB, 2 cases of heterotopic pregnancies, 1 case of elderly cornual ectopic and 2 young cases reporting one with repeated episodes of gastritis and other with post tubectomy status. The cases were managed accordingly using surgical methods. Ectopic pregnancy is like a tornado which if not diagnosed in time may prove fatal. Atypical presentation of ectopic pregnancies not fitting into the well-known triad of ectopic pregnancies these days add to confusion. One really needs to be ectopic minded if we actually want to avoid this catastrophe $\&$ save these young mothers.
\end{abstract}

Keywords: Ectopic pregnancy, Heterotopic pregnancy, Triad of ectopic

\section{INTRODUCTION}

Ectopic pregnancy is a master chameleon and can have myriad of presentations. In India, the incidence of ectopic pregnancy is 3.86 per 1000 live births, $2 \%$ in US and more in African states. It contributes $10 \%$ of pregnancy related deaths in India if not diagnosed in time. Evidence shows rising trends in ectopic pregnancies in recent past due to increase in RTIs/STIs, more use of contraceptives and increase in use of ART. Another important issue which add to diagnostic dilemma is the atypical presentation of ectopic pregnancies not encompassing all the features of classical triad of ectopic pregnancy. Diagnosis of ectopic pregnancy depends on good history taking and clinical examination followed by ultrasound (USG), serum $\beta$-HCG doubling time (at least $66 \%$ rise over 48 hours favoring an intrauterine pregnancy). ${ }^{1}$ Ectopic pregnancy can have a myriad of presentations and can be managed by either expectant or medical or surgical management depending on the age, reproductive history and status of other fallopian tube of the patient. Here we discussed a spectrum of ectopic pregnancies with atypical presentation and managed by medical or surgical modalities depending upon the hemodynamic status of the patient.

\section{CASE SERIES}

Case 1: Ectopic pregnancy with negative urine for Gravindex test (chronic ruptured ectopic)

28 years old lady with 1 st pregnancy after infertility treatment by caesarean section reported with irregular 
bleeding $\mathrm{p} / \mathrm{v}$ for 1 month and pain abdomen for 4 days on 13 April. Previous cycles were on 11 February/27 March. Patient reported to acute and emergency on 10 April with menorrhagia and was given tablet tranexamic acid and sent back. She started having severe pain, right lower abdomen same evening and was taken to a civil practitioner who treated her with $\mathrm{I} / \mathrm{V}$ fluids and pain killers and discharged next day. But her bleeding and pain persisted and she reported to gynaecology department on 13 April at 1600 hours. Clinically she was pale with pulse of $100 / \mathrm{min}$ good volume, BP-124/80 $\mathrm{mm} \mathrm{Hg}$. Abdominal examination revealed tenderness all over the abdomen more in periumbilical and right iliac fossa with rebound tenderness present. Speculum examination revealed bleeding from os. On bimanual examination there was bulky uterus with left cystic mass $4 \mathrm{~cm}$ size with cervical motion tenderness. Rt. adnexa was normal urine for Gravindex test, negative (done twice) USG (TVS) in gynae ward revealed massive hemoperitoneum with fluid upto Morrison's pouch with 4 $\mathrm{cm}$ complex cystic mass in left adnexa. Patient was taken for diagnostic laparoscopy and proceed with suspicion of ruptured left ampullary ectopic with hemoperitoneum. It was a left Ampullary ectopic which had ruptured and sealed forming an organized clot of $4 \mathrm{~cm}$. Laparoscopic left salpingectomy done and removal of hemoperitoneum done. Histopathology report confirmed ectopic pregnancy. Atypical aspect of the case was negative pregnancy test and hemodynamically stable patient despite hemoperitoneum.

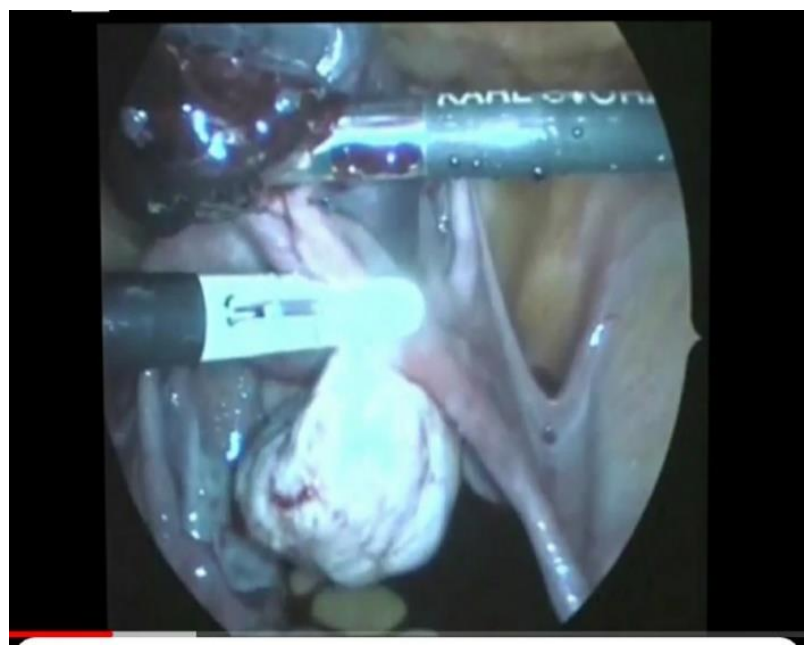

Figure 1: Ruptured Lt ectopic pregnancy laparoscopic Lt salpingectomy done.

\section{Case 2: Ectopic pregnancy manifesting like AUB}

26 year para 1 lady with previous normal delivery 3 years back presented with bleeding $\mathrm{p} / \mathrm{v}$ of 20 days duration. She had her menses on 28 December and again bleeding $\mathrm{p} / \mathrm{v}$ on 24 January with increased flow associated pain Rt. lower abdomen. On 30 January, she was treated for menorrhagia. USG done at that time in civil was NAD. On 3 February due to no pain relief and persistent bleeding, she went to second gynecologist in civil who treated her with progesterone's for AUB. On 9 February she had severe pain abdomen and fainting attacks when she consulted 3rd gynae and was diagnosed right ovarian cyst and given OCPs. Patient reported to this hospital on 14 February with bleeding $\mathrm{p} / \mathrm{v}$ and pain abdomen for 20 days. Clinically she was with pulse rate of $118 / \mathrm{min}$ regular low volume and BP-90/60 mm Hg. Abdominal examination revealed tenderness whole of lower abdomen with rebound tenderness present. Per vaginum examination showed bulky uterus with $5 \mathrm{~cm}$ size adnexal mass on right side tender with cervical motion tenderness present and left fornix was NAD. USG (TVS)-5 $\mathrm{cms}$ size right to mass present with fluid in POD. Urine for Gravindex test was positive. Patient was diagnosed Rt. ectopic pregnancy (ruptured) laparotomy findings-hemoperitoneum 1.5 liters bulky uterus left tube and ovary normal right tube ampullary ectopic ruptured and formed tubo-ovarian mass with some products spilling into POD right salpingectomy done with, adhesiolysis between Rt tube and ovary postop Hb-10.3 g/dl. Histopathology confirmed ectopic pregnancy. Atypical aspect was the presentation like a case of AUB but no one attempted to do a pregnancy test in a young reproductive age women with irregular bleeding $\mathrm{p} / \mathrm{v}$.

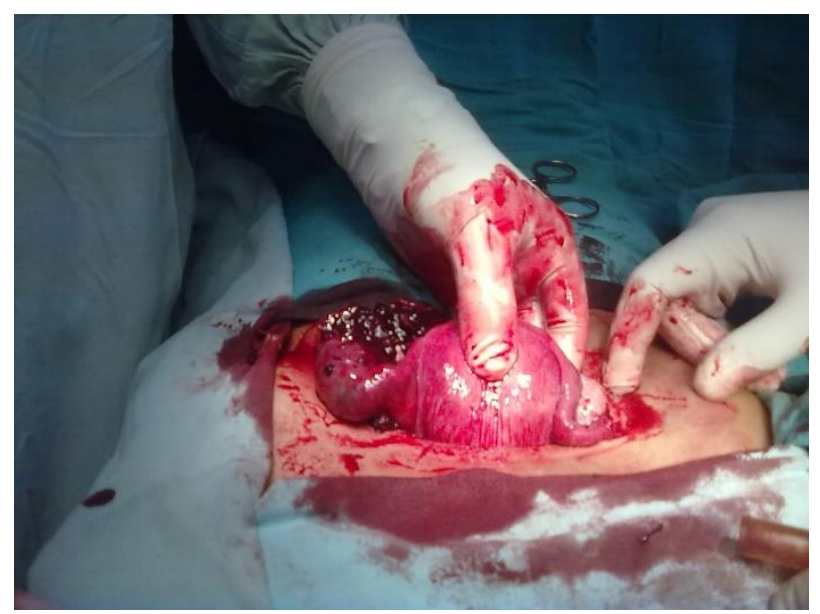

Figure 2: Ruptured right ampullary ectopic pregnancy.

\section{Case 3: Ectopic pregnancy with post tubectomy status}

26 years old w/o a serving soldier para 2 lady, tubectomy done 2 years back came with pain abdomen of 6 hours duration involving right iliac fossa on 9 April. Patient had similar complaints 25 days back when treated with painkillers and relieved. Patient had dyspepsia. Her cycles were regular 3/28 days LMP-8/3/13 but scanty bleeding. Clinically there was no pallor with pulse- $88 / \mathrm{min}$, BP104/70 mm Hg. However she had tenderness all over the abdomen. Bimanual examination showed bulky uterus, right fornix tender with $6 \mathrm{~cm}$ size cystic mass. Left fornix was normal. USG (TVS) in GOPD-bulky uterus with right adnexa $6 \times 5 \mathrm{~cm}$ mass with solid cystic appearance. Urine for GravindexTest was positive. Intraop hemo-peritoneum of $500 \mathrm{ml}$ with right ampullary ectopic ruptured and sealed 
due to organized clot at the site of rupture. Left tube and ovary had adhesions forming a mass, right salpingectomy done. Adhesiolysis on left side with crushing of left fimbria done. Postop period was uneventful. Ectopic pregnancy confirmed on histopathology report. Atypical aspect of this case being post tubectomy status.

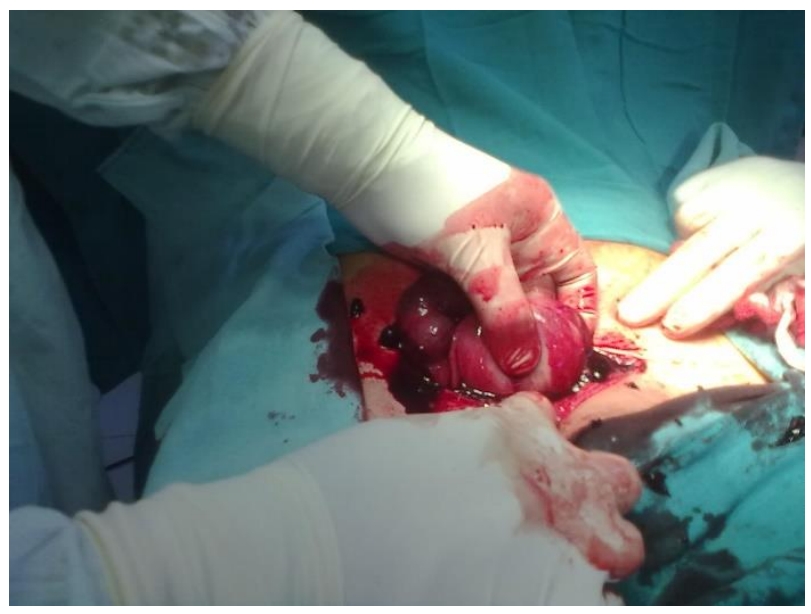

Figure 3: Ruptured right ectopic at the site of previous tubectomy.

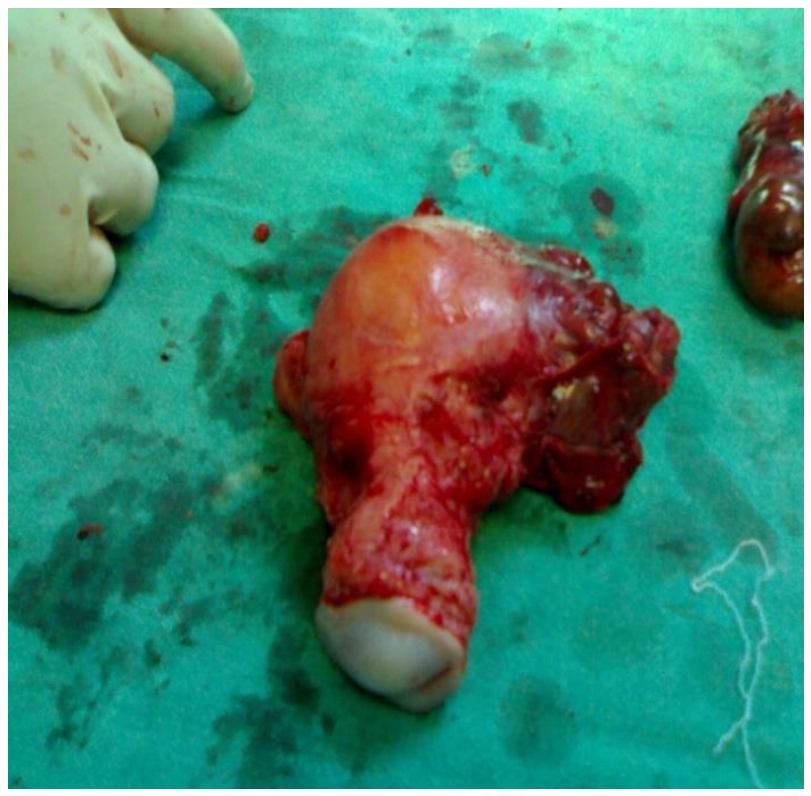

Figure 4: Left cornual ectopic pregnancy.

\section{Case 4: Elderly patient with acute abdomen with enlarged uterus}

47 years old para 3 lady presented with history of irregular bleeding $\mathrm{p} / \mathrm{v}$ and pain in abdomen for 2 months. Prior cycles irregular 5-6/20-25 days with increased flow. Patient was treated in civil as AUB with progesterone's. Clinically patient had pallor, tachycardia and tenderness all over the abdomen. Bimanual examination revealed uterus of 10 weeks size with highly tender mass $5 \mathrm{~cm}$ in left fornix and right fornix was normal. USG done in radiology department revealed left ovarian cyst (ruptured) in view of old age of the patient. Urine for GravindexTest was done which was positive. Patient taken up for emergency exploratory laparotomy with suspicion of cornual ectopic pregnancy. Intraop there was hemoperitoneum of 21 with uterus 12 weeks size with left cornual ectopic ruptured. Hysterectomy was done in this case postop Hb-7.5 gm/dl. Transfused 3 whole blood over 2 days $\mathrm{Hb}$ at discharge- $10.8 \mathrm{gm} / \mathrm{dl}$. Atypical aspect was the elderly age of the patient where the presentation was mimicking more of acute abdomen due to rupture ovarian cyst till the time GravindexTest came positive.

\section{Case 5: Incidental finding of heterotopic pregnancy}

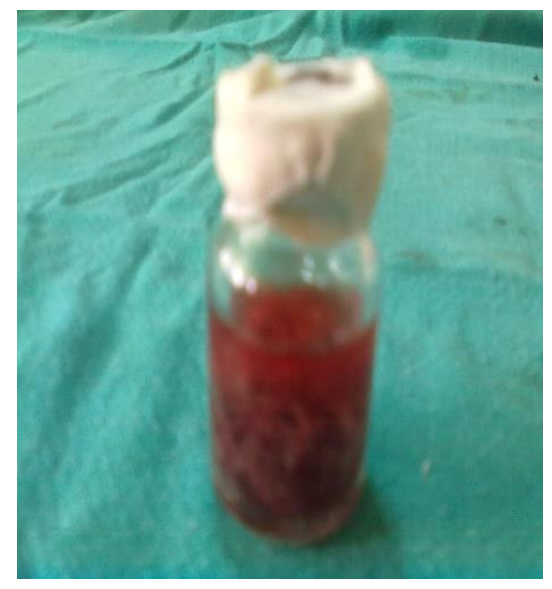

Figure 5: Products of conception.

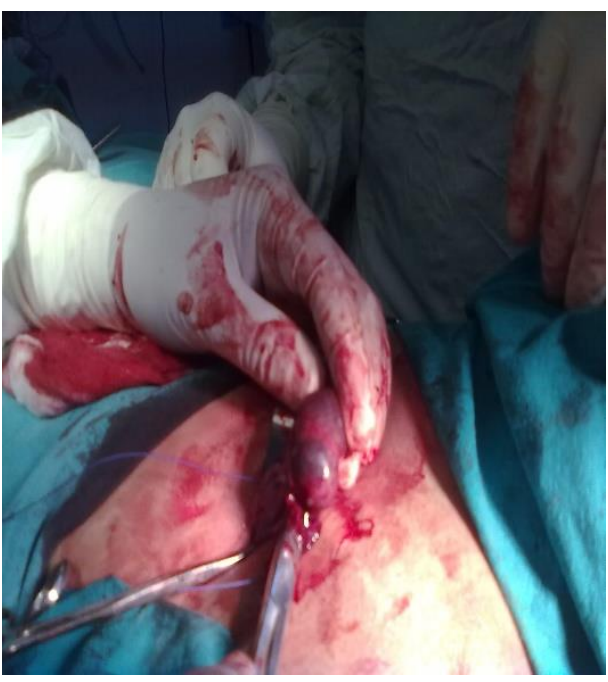

Figure 6: Left ampullary ectopic (unruptured).

29 years old para 2 lady presented with irregular bleeding $\mathrm{p} / \mathrm{v}$ for 3 months. Previous cycles were regular 3-4/28 days. Last fruitful coitus was in April. Next menses on 15 May with scanty flow for 6 days after amenorrhea of 33 days. Patient again had heavy bleeding p/v on 7 June with passage of clots for 4 days. Patient again bleeding $\mathrm{p} / \mathrm{v}$ on 19 June for 3 days with severe pain all over abdomen. Patient reported to us on 28 June. GravindexTest done in 
view of irregular bleeding $\mathrm{p} / \mathrm{v}$ was positive. Patient was hemodynamically stable with bulky uterus and tenderness in left fornix with left sided to mass $3.5 \mathrm{~cm}$. USG TVS showed RPOC in the uterine cavity with a $3 \mathrm{~cm}$ mass in the left adnexa. MTP with Lapster done as per standard guidelines. Intraop left ampullary ectopic forming flimsy adhesions with left ovary (unruptured). Left salpingectomy done right sided tubectomy by Pomeroys method. Histopathological examination confirmed rare diagnosis of heterotopic pregnancy. Atypical aspect of this case was incidental finding of ectopic pregnancy on USG when patient had actually come with incomplete abortion.

\section{Case 6: Heterotopic pregnancy with successful outcome of uterine pregnancy}

27 years old primigravida, spontaneous conception with amenorrhoea for 9 weeks and bleeding per vaginum and pain in abdomen for 1 day duration. Her LMP was 13 April and prior cycles were 4-5/30-45 days. From the history it looked like a case of abortion. Patient was hemodynamically stable with abdomen absolutely quite. Pelvic examination revealed spotting per vaginum with uterus 8 to 10 weeks and tenderness right fornix. To our surprise came the sonography report which revealed a single live intra-uterine gestation of 8 weeks 6 days and at the same time there was cystic mass seen in right adnexa approximately $2.5 \mathrm{~cm}$ in size with some free fluid in POD. So this was a case of heterotopic pregnancy with 1 single live intra-uterine gestation and another pregnancy in the right tube with hemoperitoneum suggestive of right ruptured ectopic pregnancy. This being a rare entity, patient and her relatives were explained about it and future course of terminating the right ruptured ectopic pregnancy and plan to continue the uterine pregnancy was explained. Patient after discussing all the pros and cons of undergoing surgery and its impact on uterine pregnancy finally consented to undergo laparoscopy and proceeded to manage the ruptured right ectopic pregnancy.

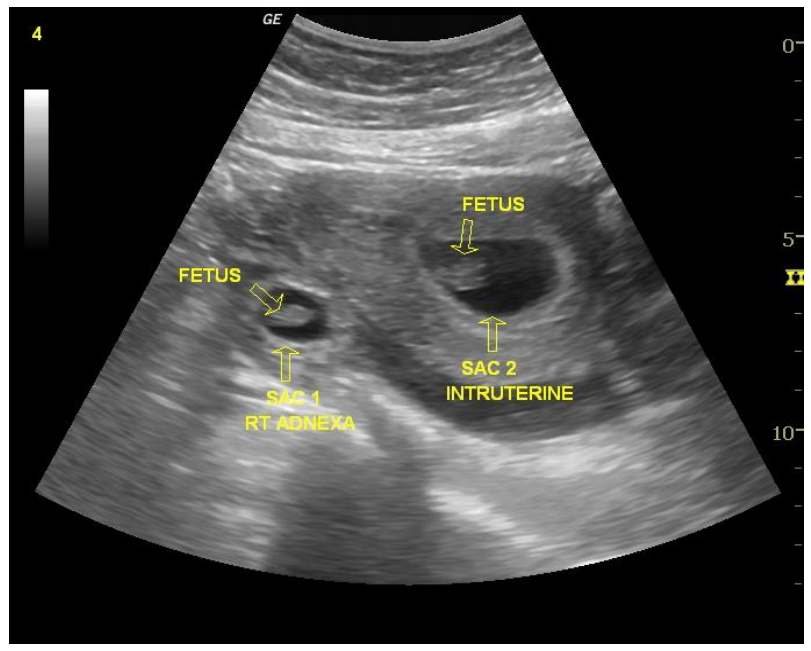

Figure 7: USG (TVS) revealing a uterine and extrauterine pregnancy in right adnexa.

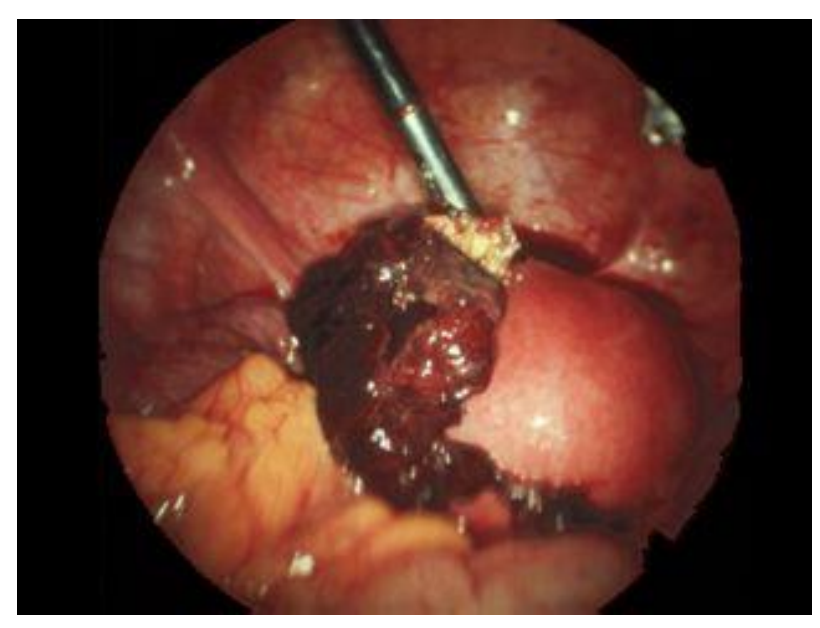

Figure 8: Right tubal ectopic (ruptured).

Laparoscopic right salpingectomy done under spinal anesthesia due to right sided ruptured ampullary tubal ectopic with hemoperitoneum of $500 \mathrm{ml}$.

Patient had an uneventful course of uterine pregnancy and emergency LSCS at 40 weeks 2 days POG was done for PROM with meconium stained liquor and an alive healthy female baby was delivered No intraoperative complication. Post-operative recovery uneventful. Atypical aspect of this ectopic pregnancy was a heterotopic pregnancy in a spontaneous conception. Heterotopic pregnancy was more commonly seen in post IVF pregnancies.

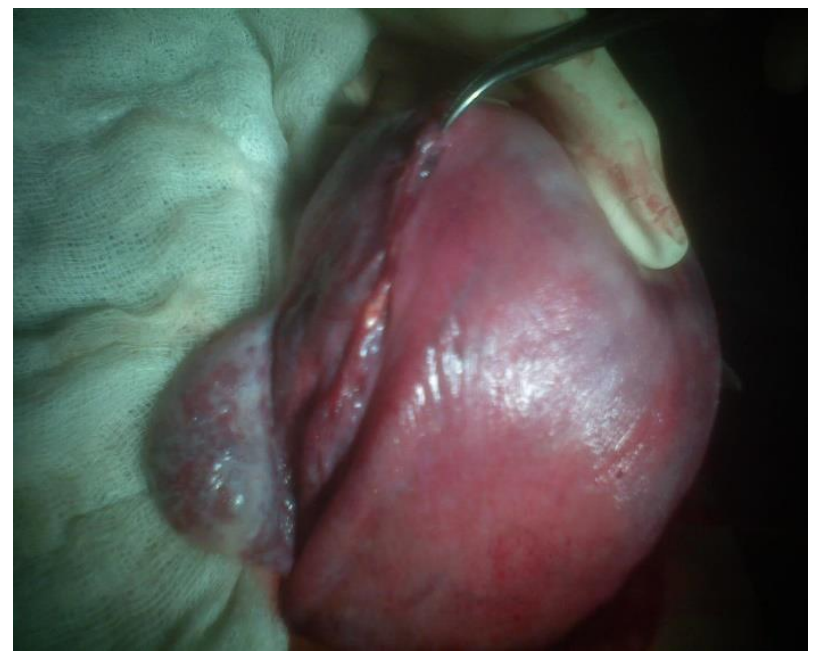

Figure 9: Intra-op uterus showing right salpingectomy.

\section{Case 7: Ectopic pregnancy manifesting as acid peptic disease/gastritis in acute and emergency}

33 years old para 2 lady came to acute and emergency with history pain epigastrium and sensation of fullness in the abdomen with weakness. Patient was evaluated by the medical officer and diagnosed as a case of APD and was started on antacids. However patient also reported off and 
on spotting per vaginum for 5 days for which she visited our OPD. On evaluation she had tachycardia with pulse rate of $102 / \mathrm{min}$ with $\mathrm{BP}$ of $100 / 64 \mathrm{mmHg}$ along with generalized tenderness in the abdomen pelvic examination revealed minimal bleeding per vaginum with bulky uterus and tender right adnexa with $4 \mathrm{~cm}$ adnexal mass in right adnexa. Urine for GravindexTest Test done in OPD was positive with USG further confirming the findings. Laparoscopic right salpingectomy done with removal of hemoperitoneum.

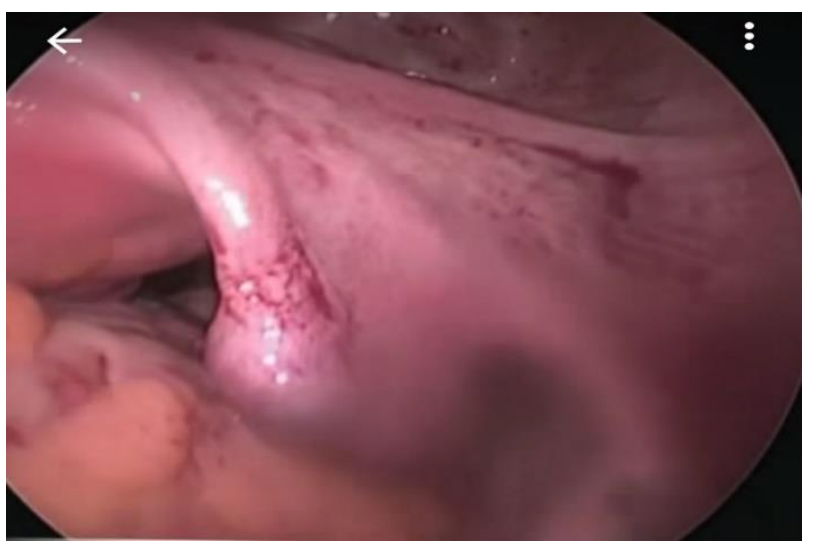

Figure 10: Right tubal ectopic.

\section{DISCUSSION}

Pregnancy in the fallopian tube is a black cat on a dark night. It may make its presence felt in subtle ways and leap at you or it may slip past unobserved. Although it was difficult to distinguish from cats of other colors in darkness, illumination clearly identifies it by Mc Fadyen 1981 .

Implantation of the blastocyst other than the normal endometrial lining of the uterine cavity results in ectopic pregnancy. $95 \%$ of the ectopic occured in the oviduct. Increase in reproductive tract infections, assisted reproductive techniques tubal operations, contraceptive failure, smoking contribute to rising trends in ectopic pregnancies. Whenever a lady came to the gynae OPD with history of amenorrhoea with a positive pregnancy test, first and foremost thing was to establish the uterine pregnancy and rule out extra-uterine/heterotopic pregnancy. Even if we were able to see the pregnancy in endometrial canal, we must see the adnexa thoroughly to rule out any ectopic pregnancy simultaneously as the incidence of heterotopic pregnancies was on the rise due to more and more use of ART procedures. Incidence of heterotopic pregnancy was $2 \%$ in IVF. Out of total heterotopic pregnancies $45 \%$ were asymptomatic, $30 \%$ present with pain and bleeding and $25 \%$ with bleeding only. One should suspect heterotopic pregnancy when height of uterine fundus more than period of gestation and there was more than one corpus luteum. Secondly there was absence of vaginal bleeding in presence of features suggestive of ectopic pregnancy and beta HCG level still high after spontaneous or induced abortion (other than molar).

\section{What is new in ectopic}

\section{Incidence}

There was increase in incidence versus case fatality rate in case of ectopic pregnancy in recent years. This was mainly attributed to increase in incidence of RTIs/STIs, more and more use of ART procedures for conception due to increase in infertility cases in recent past. Incidence of heterotopic pregnancies was also on the rise in recent past as shown in our case series also. Case fatality rate had declined due to early diagnosis because of advancement in sonography and use of quantitative beta HCG. Even increased awareness among the patients these days leads to early diagnosis. The combined use of serum beta HCG and USG definitely helped to diagnose ectopic pregnancy. If the beta HCG levels were $1500 \mathrm{mIU} / \mathrm{ml}$ or more and on TVS we were not able to see an intra-uterine gestational sac, then likely we were dealing with an ectopic pregnancy. Similarly if beta HCG levels were more than $6000 \mathrm{mIU} / \mathrm{ml}$ and we were not able to see an intra-uterine gestational sac it was likely an ectopic pregnancy. These levels of beta HCG were known as discriminatory zone of beta HCG. If beta HCG doubling time was $>48$ hours then ectopic pregnancy will be confirmed. Ring of fire pattern seen on colour Doppler in case of an adnexal mass favours ectopic pregnancy. Bagel' sign, hyperechoic ring around gestational sac in adnexal region. Blob sign, seen as small in conglomerate mass next to ovary with no evidence of sac or embryo. Other investigations like serum progesterone levels, Culdocentesis and D and $\mathrm{C}$ can also aid in diagnosing ectopic pregnancy. Serum progesterone levels between 5 to $15 \mathrm{ng} / \mathrm{ml}$ were suggestive of ectopic pregnancy. On Culdocentesis if there was fresh non clotting blood it was suggestive of ruptured ectopic pregnancy. Dilatation and curettage showing absence of lacy frond like structure floating in saline are favouring an ectopic pregnancy. If still there was a dilemma in diagnosis of ectopic pregnancy, diagnostic laparoscopy was the best modality to look for an ectopic pregnancy.

\section{Methods to early diagnose Ectopic}

Unruptured ectopic pregnancy can be confused with normal intra-uterine pregnancy. ${ }^{2}$

Classical triad was present in $50 \%$ of patients with rupture ectopic. Pain was the most constant feature in $95 \%$ patients, was variable in severity and nature. Amenorrhoea was seen in $60-80 \%$ of patients. There may be delayed period or slight spotting at the time of expected menses. Vaginal bleeding can be scanty dark brown in color associated with feeling of nausea and vomiting. Combined approach with clinical examination, TVS and HCG was helpful for confirmation in almost all the cases. Ectopic pregnancy can be managed by expectant, medical and surgical methods. If TVS showed no intrauterine 
pregnancy with beta HCG level >1500 IU/l, it was likely a case of extra-uterine pregnancy. Chronic ectopic can be diagnosed by high clinical suspicion. Patient had previous attacks of acute pain from which she has recovered. She may have amenorrhea, vaginal bleeding with dull pain in abdomen and with bladder and bowel complaints like dysuria, frequency or retention of urine \& rectal tenesmus. Features of shock were absent. Tenderness and muscle guard on the lower abdomen. A mass may be felt, irregular and tender. Vaginal mucosa looks pale, uterus may be normal in size or bulky, ill-defined boggy tender mass may be felt in one of the fornices. Urine for Gravindex test can be cessation of HCG production.

\section{Management}

Ectopic pregnancy was managed conservatively when HCG levels were low and it resolved by itself in $88 \%$ patients with initial HCG less than $200 \mathrm{mU} / \mathrm{ml} .3$

Falling trends in HCG levels were the most common parameter used for successful expectant/medical management but tubal rupture can still occur even with falling and low HCG levels. Methotrexate (MTX) was the drug of choice for medical management of ectopic pregnancy. Contraindications to use of MTX were hemodynamically unstable patient, ruptured ectopic pregnancy, poor compliance, gestational sac larger than $3.5 \mathrm{~cm}$, fetal cardiac activity, breastfeeding, immune deficiency, liver and renal disease, pre-existing blood dyscrasias, active pulmonary disease and peptic ulcer disease. $^{4}$

Medical management could be a single/double/multiple doses of MTX.

Approximately $15 \%$ to $20 \%$ of patients require single and $54-56 \%$ require multiple dose., 5 Surgical management was done by laparotomy or laparoscopy depending on the expertise of gynaecologist. Earlier it was the notion that ipsilateral oophorectomy decreases the chance of recurrence of ectopic but subsequent studies have found no such advantage. ${ }^{7,8}$

Salpingostomy was preferred over salpingectomy in cases where contra lateral tube was damaged and patient was desirous of fertility. Salpingostomy carried a risk of persistent pregnancy in patients with high starting $\beta$-HCG levels, early gestations and small ectopic pregnancies $(<2$ $\mathrm{cm}$ ) thereby requiring weekly follow up with beta HCG. ${ }^{9}$ Laparoscopically and MTX treated patients have similar reproductive outcomes. ${ }^{10,11}$ Surgically administered medical management aim was trophoblastic destruction without systemic side effects, injection of trophotoxic substance into the ectopic pregnancy sac or into the affected tube by laparoscopy or ultrasound guided (transabdominal /transvaginal) or with falloposcopic control.

The choice of surgical treatment did not influence the posttreatment fertility, but prior history of infertility was associated with a marked reduction in fertility after treatment. Making the choice, Chaperon et al 1993 had described a scoring system, based on the patient's previous gynecological history and the appearance of the pelvic organs, to decide between salpingostomy/salpingotomy/salpingectomy.

Table 1: Chaperon scoring system.

\begin{tabular}{|ll|}
\hline Fertility reducing factor & Score \\
\hline Antecedent one ectopic pregnancy & 02 \\
\hline $\begin{array}{l}\text { Antecedent each further ectopic } \\
\text { pregnancy }\end{array}$ & 01 \\
\hline Antecedent adhesiolysis & 01 \\
\hline Antecedent tubal micro-surgery & 02 \\
\hline Antecedent salpingitis & 01 \\
\hline Solitary tube & 02 \\
\hline Homolateral adhesions & 01 \\
\hline Contra-lateral adhesions & 01 \\
\hline
\end{tabular}

The rationale behind the scoring system was to decide the risk of recurrent ectopic pregnancy. Conservative surgery was indicated with a score of 1-4 only, while radical treatment was to be performed if the score was 5 or more. This way we can prevent radical surgery in a young patient who had a low score.

The cases mentioned above were a wide spectrum of ectopic pregnancy presentation and management in modern obstetrics thus improving the fertility outcomes in these young patients.

\section{CONCLUSION}

The varied presentations described here show that ectopic can have myriad of symptoms and signs. Therefore it becomes imperative that a clinician has eagles eye to pick up these subtle signs and avoid a major catastrophe in these young patients.

\section{Funding: No funding sources \\ Conflict of interest: None declared \\ Ethical approval: Not required}

\section{REFERENCES}

1. Kadar N, Caldwell BV, Romero R. A method of screening for ectopic pregnancy and its indications. Obstet Gynecol. 1981;58(2):162-5.

2. Stovall TG, Kellerman AL, Ling FW. Emergency department diagnosis of ectopic pregnancy. Ann Emerg Med. 1990;19(10):1098-103.

3. Korhonen J, Stenman UH, Ylotalo P. Serum human chorionic gonadotropins dynamics during spontaneous resolution of ectopic pregnancy. Fertil Steril. 1994;61(4):632-6.

4. American College of Obstetricians and Gynecologists. ACOG Practice Bulletin Medical 
Management of Ectopic Pregnancy. Obstet Gynecol. 2008;111(6):1479-85.

5. Barnhart KT, Gosman G, Asnby R. The medical management of ectopic pregnancy: a meta-analysis comparing single dose and multidose regimens. Obstet Gynecol. 2003;101(4):778-84.

6. Lipscomb GH, Bran D, McCord ML. Analysis of three hundred fifteen women with tubal ectopic pregnancies treated with single-dose methotrexate. Am J Obstet Gynecol. 1998;178(6):1354-8.

7. Jeffcoate TN. Salpingectomy or salpingooophorectomy. J Obstet Gynaecol $\mathrm{Br}$ Emp. 1955;62(2):214-5.

8. Schenker JG, Eyal F, Polishuk WZ. Fertility after tubal surgery. Surg Gynecol Obstet. 1972;135(1):746.
9. Gracia CR, Brown HA, Barnhart KT. Prophylactic Methotrexate after linear salpingostomy: a decision analysis. Fertil Steril. 2001;76(6):1191-5.

10. Olofsson JI, Poromaa IS, Ottander Ul. Clinical and pregnancy outcome following ectopic pregnancy; a prospective study comparing expectancy, surgery and systemic methotrexate treatment. Acta Obstet Gynecol Scand. 2001;80(8):744-9.

11. Pereira GD, Hajenius PJ, Mol BW. Fertility outcome after systemic methotrexate and laparoscopic salpingostomy for tubal pregnancy. Lancet 1999:353(9154):724-5.

Cite this article as: Bhardwaj B, Menon A, Nandy S, Santosh. Atypical ectopic pregnancy-a nightmare for the gynaecologist. Int J Reprod Contracept Obstet Gynecol 2021;10:4304-10. 